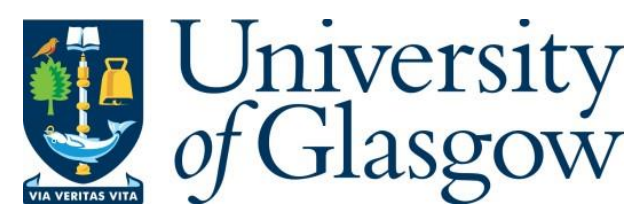

Maguire, R., Pert, C., Baines, S., Gillooly, A., Hastings, R. P., Hatton, C., Dagnan, D. and Jahoda, A. (2022) Adapted guided self-help booklets for supporting the well-being of people with intellectual disabilities during the COVID-19 pandemic: an evaluation of impact. Tizard Learning Disability Review, (doi: 10.1108/TLDR-08-2021-0024).

There may be differences between this version and the published version. You are advised to consult the publisher's version if you wish to cite from it.

https://eprints.gla.ac.uk/263323/

Deposited on: 14 January 2022

Enlighten - Research publications by members of the University of Glasgow https://eprints.gla.ac.uk 


\section{Adapted guided self-help booklets for supporting the well-being of people with intellectual disabilities during the COVID-19 pandemic: an evaluation of impact}

\section{Introduction}

Self-help materials have a strong evidence base as first line interventions for commonly occurring psychological problems like depression and anxiety (Cuijpers and Schuurmans, 2007; Cuijpers et al, 2010). A drawback for people with intellectual disabilities is the level of literacy required to use resources of this nature, hence the recommendation of guided selfhelp resources which can still be accessible and used with the support of family member, worker, or friend. Many ad hoc guided self-help resources have been developed and used in clinical services (Chaplin and Marshal Tate, 2017), and one recent study using case series design had promising findings in relation to depressive symptoms and the acceptability of the approach (Chaplin et al, 2017).

It was challenging for people with learning disabilities to access specialist mental health support during the coronavirus pandemic despite considerable unmet need (Flynn et al, 2021). There was a need for materials that could be used on an outreach basis to tackle emotional distress and promote the wellbeing of people with intellectual disabilities. Hence a set of guided self-help booklets which had been carefully researched as part of a large-scale randomised control trial (RCT) examining the use of psychological therapies for people with intellectual disabilities and depression (Jahoda et al 2017) were re-purposed to take account of the particular challenges of the Covid-19 pandemic and the ensuing restrictions. The new versions of the booklets were produced within weeks of the first lockdown, including a new introductory booklet to help people understand the purpose of the different booklets and a booklet about anxiety which followed the same carefully developed and tested format as the four original booklets: Feeling Down, A good night's sleep, You can do it and Sort it out. This included stories about characters facing particular difficulties and trying out new ways of coping, checklists of ideas for positive change, and an opportunity for individuals to make their own plans to try out their new learning. A guidance sheet was produced to accompany each of the booklets, to help the family member, support worker, or professional to support their use with someone with intellectual disability. A relaxation video was also produced. Individuals and their supporter were able to choose the booklet or booklets they thought would help them to address their particular emotional difficulties or deal with important ways of staying well. Overall, a series of six adapted guided self-help booklets and a relaxation video were made available (see Table 1). These booklets adopted a psycho-educational approach, aiming to increase people's understanding of emotional difficulties and to identify coping mechanisms and lifestyle changes that could improve or help to maintain people's emotional wellbeing.

Table 1 about here

The University team at Glasgow University worked collaboratively with the Scottish Commission for Learning Disabilities (SCLD) to disseminate the booklets and video. SCLD is an umbrella organisation with links to third sector and statutory organisations from throughout Scotland. All the booklets were hosted on the SCLD and NHS Education Scotland websites. Current versions of the materials can be found at the following link: www.scld.org.uk/update-to-the-covid-19-guided-self-help-booklets. Welsh and Dutch translations of the booklets were also produced, along with a Canadian version.

The evaluation was conducted by the research team at Glasgow University in collaboration with SCLD and with the support of colleagues at the Universities of Warwick and Lancaster. This paper examines the reach and impact of the booklets for people with intellectual disabilities who were struggling with emotional distress because of the pandemic. 


\section{Methods}

Ethical approval for data collection for the impact evaluation was granted by the University of Glasgow, College of Medical, Veterinary and Life Sciences Ethics Panel. Consent was obtained from all the participants who took part in the evaluation.

Downloads and requests for copies of the booklets were recorded.

The aim of the interviews with people with intellectual disabilities was to explore their views and experience of using the booklets. The semi-structured interviews were conversational and focused on how people had used the booklets, what they liked/disliked about them and whether, and how the booklets had helped. Data were collected from 13 people with intellectual disabilities, by individual phone $(n=4)$, online interviews $(n=4)$ or online focus groups interviews $(n=5)$. People with intellectual disabilities were approached by the organisation that supplied them with the booklets and informed about the evaluation. Participants were white Scottish, aged 23 to 70 years old and lived in rural and urban areas in a variety of settings.

The aim of the supporters' focus groups was to explore supporters' experience of using the booklets. The topic guide focused on supporters' views on the engagement, content and accessibility of the booklets, and the barriers and facilitators to delivering them. Twenty five supporters (professionals $(n=9)$, support workers $(n=4)$, family carers $(n=4)$, and social care managers $(n=8))$ took part in the online focus groups.

The online survey was developed by the research team using the Jisc Online Survey. The survey aimed to ascertain the views of family carers, support workers and professionals, who had supported individuals to use the booklets. The link was sent to all organisations and individuals who had requested the booklets from SCLD. Forty individuals completed the survey. Most respondents were from social care (18), health (7), and education (4) sectors, others were family members (3), volunteers (1), friends (1) and one individual with intellectual disabilities. As the survey was anonymous, it is unknown whether any of the respondents also took part in the focus group interviews.

\section{Analysis}

Descriptive statistics were obtained for downloads of the booklets, distribution of hard copies, and for each of the responses to the survey questions. The interviews were recorded and transcribed. Content analysis (Ritchie and Lewis, 2003) was carried out using a framework approach to identify participants' use, experience and views of the booklets. The guide for individual interviews and the topic guide for the focus groups provided the framework for the content analyses.

\section{Downloads and requests for booklets}

\section{Results}

The booklets were made available on the SCLD website in April 2020 but there was no facility to record downloads until June 2020, between June 2020 - November 2020 there were 5224 downloads of booklets. The booklets were translated into Dutch and Welsh, and Canadian versions of the booklets were produced. In the Netherlands, there were 5,535 downloads between August 2020 -January 2021. Up to the end of November 2020, there were over 450,000 unique visits to the website hosting the booklets in Canada. To address the potential digital exclusion of people with intellectual disabilities funding was obtained to provide printed copies. A total of 12,555 hard copies were distributed across Scotland. 


\section{People with intellectual disabilities' views and experiences}

\section{Use of the booklets}

While some participants had gone through all the booklets, others only used the ones which they thought would be most helpful to them. Most people used more than one booklet to help address the difficulties they were experiencing due to the Covid-19 pandemic.

\section{The stories}

All participants liked the stories about the impact of the Coronavirus on other people's lives. They felt the stories resonated with their own experience and found it reassuring to know that they were not alone in struggling with the impact of the pandemic.

'It helped to know that others were finding it difficult'. (middle aged woman)

"I liked - the feeling anxious. It talked about how folk get fed up and it's just like yourself." (middle aged man)

\section{Making plans}

The participants also appreciated being able to personalise the booklets. This involved selecting their own particular problems or preferences from the checklists provided and making plans from the ideas generated by the booklets. Working on these sections of the booklets also opened up opportunities for discussion with the person who was supporting them. One young man explained how he had used the Feeling anxious booklet and how it had helped him.

'Different things made me anxious, so used the feeling anxious booklet and I wrote them down and then I worked out ways to feel less anxious. I talked to the people who support me. I looked at the story - it helped me to talk about things that made me anxious. It helps me cope.'

Several people made similar comments, about how helpful it had been to talk about their problems. They also spoke of how useful it was to write things down and to make a plan.

I have trouble sleeping so the good night's sleep booklet helped - used the booklet to make a plan. I filled in the wee bit at the back about things that helped my sleep routine. It seems to be working for me - cutting out caffeine and listening to books at night is working for me. (young man)

\section{Making real change}

Participants found the suggestions in the booklets useful and commented on the particular actions they had taken as a result of reading the booklets. For example, one man said he had started to 'phone his brother or a friend in the evening when he was feeling low and felt that had helped him.

The participants who used the You can do it booklet (about increasing activity) all commented on how the booklet gave them ideas of things they could do at home during the pandemic, whatever their situation.

Gave us ideas of things to do - gardening, walking, jigsaws, board games, some housework. (middle aged woman, wheelchair user) 
Some participants also commented that reading through the booklets with someone was something to do and constituted an activity in its own right.

The design of the booklets

A few people also commented on the layout and design of the booklets.

"I liked the layout of it with the grids and the tick boxes and the bright colours helps and the way they suggest things to do." (young woman)

\section{Booklets made a difference}

The majority of participants talked about the difference that the booklets had made to their mood, sleep patterns, or their ability to cope with the changes in their lives due to the Coronavirus pandemic.

I'll look at them when I'm feeling a bit low or anxious. I think they are pitched at the right level.. Really helpful. (young woman)

I'm getting all of that under control. Ideas of what I can do when I'm in the house myself - things are going in the right direction (young man)

They've made me more open - more able to talk about things (young man)

Only one person stated that the booklets had been unhelpful. She had been unable to see her daughter during the initial lockdown and nothing could reduce her sadness at this separation. Nonetheless, she did feel that the booklets had motivated her to remain active at a time when it was difficult to do so.

\section{Moving forward - ideas for improvement}

Participants recommended that the booklets should be updated to address the challenges of coming out of lockdown. Some people were anxious about what life might look like and felt that a booklet about coping with change would be helpful. A few participants raised issues relating to the accessibility of the booklets and suggested more pictures and that an audio version of the booklets could be produced.

\section{Supporters' views - findings from online focus groups}

\section{Guidance and Delivery}

The majority of supporters in the had not used the guidance sheets accompanying the booklets or read through the booklets prior to delivering them to the people they supported. The discussions suggested that this was largely due to their eagerness to use the booklets. As one support worker explained:

\section{I was just so excited to get started with them. (support worker)}

Face-to-face delivery of the booklets was the most commonly used approach and all supporters said this was their preference. One professional said she had delivered booklets online with reasonable success but attempts to deliver the booklets by telephone appeared problematic as it was reported to be more difficult to engage people with the materials using the telephone.

During the initial focus group concerns had been raised that support workers' time and shift patterns might be a barrier to delivering the booklets. However, the discussions in the subsequent groups appeared to indicate that support staff found ways of including the booklets as part of their regular input with the person. 


\section{Engagement and ownership}

There was a consensus amongst all participants that having hard copies of the booklets was a significant factor in facilitating engagement with the booklets, for both the supporter and the person with learning disabilities. Parents and professionals spoke about the plethora of resources that were available online at the onset of the pandemic and welcomed a simple, straightforward printed resource.

We felt overwhelmed as professionals in terms of thinking about our duty of care... The booklets are clear, simple, it's actually physically something that we can do. It was something we could trust; it was also something about having ownership of a physical object. (professional)

Support workers also stressed the sense of ownership that people with intellectual disabilities felt about having printed copies, "It was their own booklet, to write in and look back on." They commented on how a physical resource was "more universally accessible compared to online activities" and how it enhanced communication between staff and service users.

Many family carers and support staff spoke of the value of the booklets, not only for the people they were supporting, but for themselves and other supporters and services.

Booklets are useful for everyone, not just people with learning [intellectual] disabilities so that makes them more accessible - useful for staff, staff have used them for their families. I also use it with my children! (support worker)

\section{Design, Quality and engagement}

Supporters drew attention to how the design, layout and content of the booklets made them more accessible, helping to facilitate communication and engagement. They appreciated the quality of the printed booklets and commented that they "really liked that they didn't looked particularly "learning disability"'.

All supporters thought that the combination of individual stories, facts, and checklists, helped make the booklets engaging and relevant to the individuals with intellectual disabilities. They felt that the process of going through the booklets together provided the individuals they were supporting an opportunity to talk about their feelings and experiences.

I just felt that they were very relatable and it's better for somebody who's going through a difficult period to feel as if they are not alone, that other people are going through it too. (support worker)

\section{Selection of booklets}

The majority of supporters had selected particular booklets to meet the needs of the people they were supporting. The Feeling down and Feeling anxious about Coronavirus booklets were used most often by support workers and were thought to provide helpful suggestions for improving their wellbeing.

While some supporters felt that the Sort It out booklet was quite complex for the people they supported, others tried to adapt it to the person's situation. One of the professional participants particularly liked the Sort it out booklet because she felt that it encouraged "people to think about one problem at a time". 
The 'You can do it' booklet which focused on the benefits of keeping active was also cited as helpful for establishing new routines, motivating people to be active as well as giving them ideas of things to do.

I feel that we used the getting active one quite a lot - it gave them motivation to do it... reading the booklet in that time and place gave her the motivation - actually to think that will help me. (support worker)

The respondents also reported finding the booklets useful as people's moods fluctuated during the pandemic.

The mental health of the service users can dip. It can be positive for a couple of weeks then dip, and that's where we would go back to the booklets, you know say that it's okay to feel like that. Or, what can we do today to make your day a bit better? (professional)

\section{Changes}

Both professionals and support workers discussed the potential benefits of having a short training video about delivering the booklets. They felt that a basic training video could help supporters to be more consistent in their approach and increase their confidence.

In common with the views of those with intellectual disabilities, it was suggested that the booklets could be adapted to help address people's anxieties about coming out of the pandemic and the uncertainties surrounding changing rules and circumstances. There was general agreement that the booklets would be of continued use beyond the pandemic.

\section{Online Survey}

All supporters had used more than one booklet and they all reported finding the accompanying guidance very or a little useful. The most common method of delivery was face-to-face (29). Other supporters used an online platform such as zoom (4), made audio (4) or video (2) calls, or used a mixture of methods. With the exception of the Sort it out booklet, most supporters reported going through the booklets with people more than once and many individuals also used the booklets on their own. Thirty supporters stated that it had been easy to engage the person with the booklets. Three respondents found it very difficult, and the remaining seven a little difficult. We did not collect data as to why engagement was difficult. The majority of respondents found the stories, images, and checklists of ideas and issues that people could select and personalise for each individual booklet to be helpful. The main barrier for support workers who were delivering the booklets was lack of time, along with organisational difficulties and difficulties caused by shift patterns. Interestingly, few supporters reported that a lack of confidence and experience were barriers. When questioned about other barriers, supporters indicated that restrictive Covid-19 pandemic rules had made it difficult to deliver the booklets face-to-face.

\section{Did the booklets make a difference?}

Respondents were allowed to select more than one option from the list shown in Table 2. Helping the person to realise that they were not alone and a willingness to talk about their difficulties were the most frequently endorsed items. However, supporters also identified specific improvements to health and well-being in areas covered by the booklets, including mood and anxiety.

Table 2 about here 


\section{Conclusions}

There are limitations to this impact evaluation. For example, we do not know for certain how many people who requested hard copies or downloaded the booklets actually used them. However, the quantitative and qualitative data we have gathered provide evidence of the considerable reach and impact of the booklets. The large number of downloads and requests for booklets highlighted both the need and demand for resources to help people with intellectual disabilities cope during the coronavirus pandemic. The evidence also suggests that the booklets had proved helpful. Having a number of booklets covering different issues was appreciated, as it allowed the person with intellectual disabilities and their supporter to actively select the booklets that they wanted to work through. People with intellectual disabilities and their supporters viewed the booklets as being engaging and relevant to their lives. It may have been these qualities that helped to raise awareness that others shared the same feelings and faced the same challenges as them, making it easier to talk about their feelings more openly.

Although downloads of the booklets have been made available on-line, the supporters and people with intellectual disabilities placed considerable value on possessing printed copies. The supporters believed that physical copies conferred a sense of ownership, an object the individuals with intellectual disabilities could keep, refer back to, show to others, and continue to work with. The original intention of producing the printed copies was to avoid digital exclusion. What had been overlooked was the potential advantages of having printed resources. This may be a vital consideration, if online resources may not be everyone's preference or services lack the ability to produce high quality printed copies of resources.

The quality of the booklets and their professional design seemed to be greatly appreciated by both supporters and people with intellectual disabilities. Sadly, this may reflect the fact that there are few well produced resources which are made widely available for people with intellectual disabilities. Perhaps for this reason, one of the supporters lauded the 'non learning disabilities' look of the booklets. Being professionally produced seemed to make the booklets more inclusive, with some of the supporters expressing interest in the content. Having resources that are valued by those who help deliver them, family carers and support workers, as well as who they are developed for, may be key to the dissemination and uptake of these type of guided self-help resources.

Interestingly, lack of experience or confidence were rarely seen as barriers to delivering the booklets by family members or support workers. In fact, one of the issues was that supporters did not always read the guidance before going through the booklet with an individual. The suggestion of a basic online training video may be a helpful idea not just for supporters but also to introduce the booklets to people with intellectual disabilities who might wish to use them.

Specific ideas about changes to the booklets were suggested, to take account of the evolving situation with COVID-19 and the associated restrictions. These ideas have been carefully considered and have contributed to updated versions of the booklets which have been produced and are being disseminated through SCLD. However, the learning from this evaluation perhaps highlights the continuing need for resources of this nature, beyond the pandemic. People with intellectual disabilities have had longstanding difficulties with accessing psychological services and the system tends to be reactive, offering help when people reach crisis. There may also be a need for research to examine more accessible and proactive approaches, which aim to help people stay well and lead more fulfilling lives. 


\section{References}

Chaplin, E., Craig, T., McCarthy, J., \& Bouras, N. (2017). The SAINT: A Guided Self-Help Approach for People with Intellectual Disabilities. Journal of Mental Health Research in Intellectual Disabilities, 10(3), 237-252.

Chaplin, E., \& Marshall-Tate, K. (2017). The case for guided self-help for people with intellectual disabilities. Advances in Mental Health and Intellectual Disabilities.

Vol. 11, Issue. 3, 126-130.

Cuijpers P, Donker T, van Straten A, Li J, Andersson G. (2010) Is guided self-help as effective as face-to-face psychotherapy for depression and anxiety disorders? A systematic review and meta-analysis of comparative outcome studies. Psychol Med. Dec;40(12):194357. doi: 10.1017/S0033291710000772. Epub 2010 Apr 21. PMID: 20406528

Cuijpers, P., Schuurmans, J. (2007) Self-help interventions for anxiety disorders: An overview. Curr Psychiatry Rep 9(4), 284-290 doi: 10.1007/s11920-007-0034-6. PMID: 17880859

Jahoda, A., Hastings, R., Hatton, C., Cooper, S. A., Dagnan, D., Zhang, R., ... \& Scott, K. (2017). Comparison of behavioural activation with guided self-help for treatment of depression in adults with intellectual disabilities: a randomised controlled trial. The Lancet Psychiatry, 4(12), 909-919.

Jisc Online Survey: https://www.jisc.ac.uk/online-surveys

Ritchie, J. and Lewis, J. (2003). Qualitative research practice: A guide for social science students and researchers. London: Sage. 
Table 1 Description of the booklets and relaxation video

\begin{tabular}{|c|c|}
\hline Coronavirus introduction & $\begin{array}{l}\text { Introduction to the booklets that are available and find out what } \\
\text { the person might find most helpful. } 12 \text { pages. }\end{array}$ \\
\hline Feeling Down & $\begin{array}{l}\text { Explains how everybody can feel down and how people feel } \\
\text { down for different reasons. The aims of the booklet are to help } \\
\text { people understand why they are feeling down and to help them } \\
\text { to talk about their emotions. } 12 \text { pages. }\end{array}$ \\
\hline Feeling anxious about Coronavirus & $\begin{array}{l}\text { Feeling anxious about Coronavirus booklet: Explains how } \\
\text { everybody can feel anxious and that people feel anxious for } \\
\text { different reasons. The aims of the booklet are to help people } \\
\text { understand why they are feeling anxious and learn about ways } \\
\text { to stay calm and feel in control. } 16 \text { pages. }\end{array}$ \\
\hline A good night's sleep & $\begin{array}{l}\text { About helping people to sleep well. It explains how this can be } \\
\text { a problem if people's routine changes or if they are feeling } \\
\text { down or anxious. The aims of the booklet are to help the person } \\
\text { to sleep better and to show how sleep is important for } \\
\text { everyone's wellbeing. } 16 \text { pages. }\end{array}$ \\
\hline You can do it & $\begin{array}{l}\text { About exercise and staying active, which can improve } \\
\text { mood. The booklet is about increasing the person's activity } \\
\text { to help lift their mood and sense of wellbeing. The aims of the } \\
\text { booklet are to help the person gain insight into the role that } \\
\text { exercise and activity can play in improving wellbeing, and to } \\
\text { help the person to think about and plan activities they would } \\
\text { like to do. } 12 \text { pages. }\end{array}$ \\
\hline Sort it out & $\begin{array}{l}\text { About problem solving. The idea is to help the person learn } \\
\text { about an effective way of solving their problems that they can } \\
\text { use in their everyday lives. The aims of the booklet are to help } \\
\text { the person understand the benefits of problem solving and learn } \\
\text { how to do it. } 16 \text { pages. }\end{array}$ \\
\hline How to Relax video & $\begin{array}{l}\text { A } 10 \text { minute film providing instruction in breathing exercises to } \\
\text { promote relaxation. }\end{array}$ \\
\hline
\end{tabular}


Table 2 What difference did the use of the booklets make to the person you were supporting?

\begin{tabular}{|l|l|}
\hline Difference made & Number \\
\hline They are reassured that other people have similar problems & 23 \\
\hline They are more willing to talk about their problems & 18 \\
\hline Their mood has improved & 16 \\
\hline They have a better understanding that others are in a similar situation & 15 \\
\hline They are less anxious & 14 \\
\hline They are coping better generally & 10 \\
\hline Their sleeping patterns have improved & 9 \\
\hline They are doing more exercise & 9 \\
\hline They are less depressed & 6 \\
\hline The booklets made no difference & 1 \\
\hline
\end{tabular}

